\title{
The impact of the confinement motif on selected works of American Literature
}

\author{
Ágnes Bodnár
}

\section{I}

In my essay I am focusing on three different aspects of confinement in the case of women victimized by physical or metaphysical captivity. The reason for choosing these stories was the actual description of physical captivity or the restrictions and restraints on one's movement. My inquiry is primarily guided by Enikő Bollobás' theory of the performative, along with Maurice Merleau-Ponty's and Emanuel Levinas' views on intersubjectivity. In addition to applying these theoretical models to the selected texts I will identify potential parallels with the given plots and the main motifs of Indian captivity narratives.

Bollobás asserts that the subject can be performed in two ways, either theatrically, replaying the existing scripts, thus projecting a performance according to the expectations of power while reproducing the ruling ideologies. The other approach is to create new identities, or promoting agency in the form of what she calls the radical performative. The concept of intersubjectivity, implying the recognition of the Other, is a fundamental motif or trope of any multicultural encounter including the confinement of the white woman in the hands of Native Americans. The recognition of the Other in the subject implies affective intersubjectivity, while antagonistic intersubjectivity is based on objectification.

Harriet Jacobs' Incidents in the Life of a Slave Girl (1861) provides a glimpse at how slavery is coupled with sexual exploitation, Charlotte Perkins Gilman's "The Yellow Wallpaper" (1892) shows how a woman turns to destructive behavior to rebel against her submissive status within the institution of marriage reflecting patriarchal domination, and Gertrude Bonnin (Zitkala-Sa) reports on the forms of culture shock she suffered in a Quaker boarding school in Schooldays of an Indian Girl (1900).

\section{II}

Born to mulatto parents, Jacobs was protected from the brutal reality of slavery until age six when her mother died. Subsequently, she was forced to realize by overhearing the conversation of others that she was in fact a slave. Eventually, she 
was assigned into household slavery at the plantation of Dr. Flint, a local doctor, whose main goal was to seduce her. Although she repeatedly refused his advances, he would not relent in his pursuit. In order to escape the fate of becoming his concubine, she started a relationship with a neighboring plantation owner, $\mathrm{Mr}$. Sands, and the liaison resulted in two children. Nevertheless Dr. Flint continued to harass her and did his best to separate her from her children cared for by her grandmother. In desperation she decided to escape. She found refuge in the attic at her grandmother's house near the estate of the doctor. During her seven year hiding, she spent her time by reading the Bible and sewing clothes for children. She escaped to the North in 1842 and became one of the leading spokespersons against slavery.

An early proponent of women's rights and an author known to resort to the captivity motif, ${ }^{1}$ Lydia Maria Child, functioned as the amanuensis of the Jacobs narrative. Child's emphasis on the rectitude of Jacobs' character reinforces that she acted according to contemporary social scripts. "During the last seventeen years, she has lived the greater part of the time with a distinguished family in New York, and has so deported herself as to be highly esteemed by them" (7). Child also offers a careful disclaimer concerning the truth value of the Jacobs narrative: "I believe those who know her will not be disposed to doubt her veracity, though some incidents in her story are more romantic than fiction" (7).

Harriet Jacobs is exposed to the contemporary power represented both on the macro and micro level. The macro or social level is the slave holding society of the South, and in the individual dimension it is Dr. Flint who wishes to exercise unlimited control over her. The captivity motif is applicable both on the physical and metaphysical plane. The physical level of course is indicated by the limited space in the garret, while the metaphysical aspect is the peculiar institution of the South.

The protagonists of Indian captivity narratives such as Elizabeth Hanson, Hannah Dustan, and that of the slave narrative as demonstrated by Jacobs, display personal growth ranging from suffering objectification to achieving subject status. The central point of objectification is equivalent to symbolic death, manifested in the full denial of the protagonist's humanity. In the case of Jacobs, her symbolic death, that is, her perception as chattel or property is marked by Dr. Flint declaring that "[she] was made for his use, made to obey his command in everything; that [she] was nothing but a slave, whose will must and should surrender to his" (29). The individual dimension represented by her master is complemented by the same perception held by Southern society, which is reflected in the protagonist's appalled comment: "I never dreamed I was a piece of merchandise" (11).

1 Hobomok: The Tale of Early Times (1824) 
Jacobs' commitment to contemporary social codes is reflected by her insistence on her own virtue and the invocation of the theatrical performative. One such instance is when she informs Dr. Flint of her desire to marry a black man: "It is right and honorable for us to love each other. The man you call a puppy never insulted me, sir; and he would not love me if he did not believe me to be a virtuous woman" (61). The way she attempts to come to terms with Dr. Flint's seductive advances: "He tried his utmost to corrupt the pure principles my grandmother had instilled" (44) reiterates her dedication to a virtuous life. Moreover, she believes that with the affair with Mr. Sands she has degraded herself. She grapples with the dilemma whether she should let her grandmother know about the liaison: "I wanted to confess to her that I was no longer worthy of her love; but I could not utter the dreaded words" (86). Her choice of words: "virtuous woman, pure principles," reflect her attempt to meet the moral code of her age.

The escape from the plantation amounts to defying contemporary social scripts. She rebels against the patriarchal order and uses cunning and trickery to defeat a much more powerful enemy: "Who can blame slaves for being cunning? They are constantly compelled to resort to it. It is the only weapon of the weak and oppressed against the strength of their tyrants" (154). Her confinement within captivity compels her to take on the role of the trickster, a frequent device members of social groups deprived of economic or political power resort to. In order to mislead her pursuers into believing that she escaped to the North, she arranges that letters are sent to the Flint home from New York.

The time she spends at her grandmother's garret implies physical enclosure, while she is metaphysically captured in the institution of slavery. Unlike the Indian captivity, her physical confinement is self-chosen, yet its physical and psychological impact is similar. Her physical suffering is caused by the limited space and lack of mobility and motility. Likewise, being so close, yet so far away from her children, causes emotional anguish: "The garret was only nine feet long, and seven wide. The highest part was three feet high, and sloped down abruptly to the loose board floor. There was no admission for either light or air. [...] The air was stifling; the darkness total [...] I suffered for air even more than for light. But I was not comfortless. I heard the voices of my children" (173).

Antagonistic intersubjectivity can be recognized in her response upon Dr. Flint's assault and his refusal to let her marry a free black man: "He sprang upon me like a tiger, and gave me a stunning blow. It was the first time he had ever struck me; and fear did not enable me to control my anger. When I had recovered a little from the effects, I exclaimed, 'You have struck me for answering you honestly. How I despise you!' (61). Her reaction to the incident brings Carolyn Heilbrun's preconditioning of subject status on the capability to express anger to mind. The last 
sentence in fact can indicate subjectivation, that is, the achievement of the status of Foucault's active subject and the presence of the grammatical subject. The term "you have struck me" expresses distancing from Mr. Flint as the expression "me" clearly indicates the establishment of physical boundaries, and the verb "despise" confirms the relegation of her tormentor to abject status. Despising something or somebody connotes exclusion from one's personal horizon while implying the reinforcement of the self at the same time.

Having witnessed the brutal punishment meted out to a fellow slave and sharing his pain, she also expresses affective intersubjectivity: "I shall never forget that night. Never before, in my life, had I heard hundreds of blows fall, in succession, on a human being. His piteous groans, and his ' $\mathrm{O}$, pray don't, massa,' rang in my ear for months afterwards" (23).

Jacobs uses the captivity motif partly to raise sympathy to her plight while resorting to the Gothic to promote the goals of the abolition movement. Hiding, although voluntarily, in the garret establishes a parallel with Gilman's heroine locked in a room at the top of the "ancestral hall" or with the ominous enclosure of Bonnin at the beginning of her ordeal. Making emotional outbursts reminiscent of Mary Kinnan's captivity narrative, she juxtaposes her suffering to the general immorality of slavery: "Could you have seen that mother clinging to her child, when they fastened the irons upon his wrists; could you have heard her heartrending groans, and seen her bloodshot eyes wander wildly from face to face, vainly pleading for mercy; could you have witnessed that scene as I saw it, you would exclaim, Slavery is damnable!" (38).

Similarly to the captives of Indians, she is exposed to the extremities of the weather while hiding in her grandmother's attic: "I suffered much more during the second winter than I did during the first. My limbs were benumbed by inaction, and the cold filled them with cramp" (185). Another parallel with the captivity narrative is the protagonist acting as an amateur ethnographer as seen in the case of Rachel Plummer and Mary Rowlandson. Jacobs provides detailed information on the logistics of slavery including the diets, the food allowances, and structural aspects of that institution.

It is also noteworthy that just like in the case of the Indian captivity narrative religion plays a central role. True to the general view of religion as presented in the slave narrative, Jacobs has mixed views on the topic. She asserts that it provides comfort for her when she prays at her parents' grave: "I knelt by the graves of my parents, and thanked God, as I had often done before, that they had not lived to witness my trials, or to mourn over my sins. [...] My trust in God had been strengthened by that prayer among the graves" (138-9). But she also condemns Christianity: "When I was told that Dr. Flint had joined the Episcopal church, 
I was much surprised. I supposed that religion had a purifying effect on the character of men; but the worst persecutions I endured from him were after he was a communicant" (115).

Jacobs throughout her ordeal evolves from a victim of constant sexual harassment to someone following her own will capable of making her own decisions. The unique aspect of her experience is that she becomes a captive within the pre-existing confinement of slavery. In her case imprisonment in the attic, notwithstanding the torturous circumstances, means liberty. Her position, however, is liminal both in the physical and metaphysical sense. She is removed from the ground and is in between slavery and freedom. The attic serves as a transitional space or as a waystation between bondage and liberty. It is also ironic that she gains agency by intentionally limiting her physical mobility. In light of De Lauretis's space off theory, the grandmother's attic functions as the "elsewhere," or a space at the margin of the represented discursive space, which in the present case is the plantation of Dr. Flint, and by extension the southern slaveholding society.

Captivity, although in a different form, is the central motif in Charlotte Perkins Gilman's "The Yellow Wallpaper." The well-known story describes how a woman suffering from at that time undiagnosed post-partum depression loses touch with reality and descends into the abyss of madness. The story emphasizes both the physical and metaphysical aspects of captivity within the confines of a marriage dominated by patriarchy. The unnamed protagonist is under the full control of her husband both from a social and medical vantage point. As her "hysteria" is treated by her spouse, in addition to the paternalistic control generated by the patriarchal society, reminiscent of Foucault's concept of bio-power she is controlled medically as well. Accordingly, the protagonist is subordinated to "the life administering power subjecting one to precise controls and comprehensive regulations" (325).

At the orders of her husband she is placed in the children's nursery at the top of the "ancestral hall" with bars on the window. She is deprived of any creative activity, yet, she secretly writes down her experiences. The absolute submission to her husband is also expressed by his control of her time: "I have a schedule prescription for each hour in the day" (Gilman). On the physical level the protagonist is confined against her will and on the social level she is medically controlled by her physician husband and treated as a child. The patriarchal and medical power she faces is described by the following quote:

John is a physician, and perhaps-(I would not say it to a living soul, of course, but this is dead paper and a great relief to my mind-) perhaps that is one reason I do not get well faster. You see, he does not believe I am sick! 
[...] My brother is also a physician, and also of high standing, and he says the same thing (Gilman).

Her subordinated status has three dimensions, she is subjugated as a wife, as a woman, and as a patient. The medication given to her reinforces her husband's bio-power: "So I take phosphates or phosphites-whichever it is, and tonics, and journeys, and air, and exercise, and am absolutely forbidden to 'work' until I am well again" (Gilman). In fact, while being deprived of the tools of writing and denied of the power of expression, she manages to create her own story by describing the wallpaper and recognizing the woman imprisoned in it.

Her objectification on the part of her husband and patriarchal society is indicated by John's attitude toward her condition and how he fully disregards her views. Her repeated questions "But what is one to do?" (Gilman) illustrate her subordinated position and objectification. The question expresses helplessness, vulnerability, and lack of agency. Yet, it also suggests a potential call for action.

By accepting the romantic paternalism influenced diagnosis she acts according to contemporary social scripts, yet, she refuses to acknowledge that to herself. "I take pains to control myself-before him, at least, and that makes me very tired" (Gilman). The theatrical performative is literally applicable to the story as she puts on an act to pretend that she accepts her husband's medical and personal diagnosis of her condition. The paradox of her situation is that while deep inside she rejects the diagnosis made by her husband and contemporary society, her action eventually reinforces the original assessment of her condition. It is also ironic and shows the influence of the contemporary social expectations that she discards the idea of suicide because "a step like that is improper and might be misconstrued" (Gilman).

The statement: "I get unreasonably angry with John sometimes" (Gilman) refers to how she begins her development toward achieving subject status. Her anger will develop into a full-fledged wrath leading to the destruction of the wallpaper. This episode reinforces the original assessment of her condition, but also offers proof to Myra Jehlen's assertion that the expression of anger is a manifestation of one's power in a given situation, by extension the acquisition of agency. In light of the above mentioned events, the story describes how she advances from being a literal patient to a figurative agent.

Much like in the case of Jacobs, her exposure to power at first leads to the reinforcement of contemporary social scripts which will eventually give way to the radical performative. Her husband "hates to have her write a word" (Gilman), therefore she hides her writing, reminiscent of Mary Rowlandson keeping her Bible away from the Indians. It is also noteworthy that she locks herself into the room when she decides to "free" the "woman" captured in the wallpaper. At this point a 
multilevel captivity motif is applicable. On the metaphysical level she is victimized by the social, political and bio-power of patriarchal society. Yet, by deciding to lock herself in the room she creates a separate space for her, just like in the case of Harriet Jacobs. In a way of fighting fire with fire she responds to externally imposed captivity with internally induced confinement.

Simultaneously, the "woman" behind the wallpaper is the manifestation of the protagonist's own situation. By locking herself in she occupies Edward Soja's Third Space, not fully negating her original position, but building on it. The sympathy she feels for the "imprisoned woman" can be interpreted as a unique aspect of intersubjectivity. Affective intersubjectivity can be recognized in her concern over John and his sister Jenny being "affected" by the horrendous wallpaper. The ambiguity of intersubjectivity is illustrated by her description of Jenny: "There comes John's sister. Such a dear girl as she is, and so careful of me! I must not let her find me writing" (Gilman). As she refers to her sister-in-law as her husband's sibling, she distances herself from her and the family. While the first two sentences suggest Levinas' face to face or ethical relationship and perceiving the world from the perspective of the Other, her fear of being found out suggests an antagonistic attitude.

Her acts also imply self-empowerment. By locking herself in, she creates a space that she controls, thus, she gains agency. The circumstances, living in the attic or a confined space and experiencing emotional anguish and physical ordeal suggest a parallel with Jacobs' plight. Gilman's protagonist also appears to act like Heilbrun's ambiguous woman rejecting to live a life determined by men as she claims the right to vent her anger: "But I am here, and no person touches this paper but me,not alive!" (Gilman).

However, as her attempts to break out of the private sphere are foiled she decides to destroy the physical manifestation of her confinement, the wallpaper, or by extension, the wall. The removal of the wallpaper, that is, the surface covering the actual wall, indicates that despite removing the exterior layer, the internal structure remains untouched and her confinement continues. After her effort to convince her husband to let her go to visit her relatives is failed, she turns inward. She rejects John treating her as a father would by soothing a crying child; taking her upstairs and reading to her until she fell asleep. When John responds with a "stern, reproachful look" (Gilman) to her request to leave the place, she starts to become obsessed with the wallpaper. In fact, she jealously guards it from others and the recognition of the woman aiming to break out becomes her own plot within the gilded cage of a patriarchal marriage. 
There are things in that paper that nobody knows but me, or ever will. Behind that outside pattern the dim shapes get clearer every day. It is always the same shape, only very numerous. And it is like a woman stooping down and creeping about behind that pattern. I don't like it a bit. I wonder-I begin to think-I wish John would take me away from here! (Gilman).

Gilman consciously resorts to the captivity motif in a gothic setting to illustrate the suffering of women in the patriarchal institution of marriage. The Gothic aspect is conveyed by such terms as "ancestral hall, haunted house, optic horror, untenanted" (Gilman). The destruction of the wallpaper deemed to be "repellant, unclean, sickly" (Gilman) reinforces the ominous aspect of the setting. The "gouged floor, the pattern lolling like a broken neck" (Gilman) refer to the slow buildup of wrath in the protagonist leading to the eventual violence.

Gertrude Bonnin or Zitkala Sa, whose Schooldays of an Indian Girl presents a captivity narrative, reverses the original dynamic of the captivity experience. In this case it is the Native American who is captured and victimized by the representatives of the mainstream. The captivity of the protagonist is not the result of an attack or forceful removal from one's own surroundings. The young child is taken away from the reservation to a boarding school run by Quaker missionaries, who convince her mother to let her go in order to receive an education.

On the eastward train ride the Indian children are exposed to stares and are disapprovingly pointed at by other passengers. "Being scrutinized by fair women" and "large men riveting their glassy blue eyes" upon them brings Bonnin "on the verge of tears" (Bonnin). The paralyzing effect of the hostile gaze robs the protagonist from mobility and motility as she sat "perfectly still, with eyes downcast, daring only now and then to shoot long glances around her" (Bonnin).

Her arrival into the boarding school is only a beginning of a long series of traumatic events. She encounters the contemporary power, that is, the residential education institution representing the intention of the American government to eliminate traditional Indian culture. Her mental and emotional state is comparable to that of the female captives of Indians at the beginning of their ordeal: "It was night when we reached the school grounds. The lights from the windows of the large buildings fell upon some of the icicled trees that stood beneath them. We were led toward an open door, where the brightness of the lights within flooded out over the heads of the excited palefaces who blocked the way. My body trembled more from fear than from the snow I trod upon" (Bonnin).

She was forcefully separated from her home culture as she was compelled to change into Anglo clothes and her long hair was cut against her will. This forced haircut episode represents her subjection and ultimate objectification leading 
to symbolic death. After that, likewise to the white female captive, she loses her will and experiences psychological defeat. While at first "her spirit tore itself in struggling for its lost freedom" (Bonnin), the forceful integration into the context of the boarding school breaks her will.

When she finds out that her hair is about to be cut she makes a desperate attempt to escape a fate most disgraceful to any Indian. Despite her friend's warning that she had to submit, she resists, but her struggle is useless. Although she hides away, when she is found "she is carried downstairs, and tied fast in a chair" (Bonnin) and her hair is cut short. The result of this episode is symbolic death as she not only loses her cultural markers, but her spirit is broken as well:

Then I lost my spirit. Since the day I was taken from my mother I had suffered extreme indignities. People had stared at me. I had been tossed about in the air like a wooden puppet. And now my long hair was shingled like a coward's! In my anguish I moaned for my mother, but no one came to comfort me. Not a soul reasoned quietly with me, as my own mother used to do; for now I was only one of many little animals driven by a herder. (Bonnin)

Yet, in an attempt to reach subjectivity she repeatedly "tests the chains which tightly bound [her] individuality like a mummy for burial" (Bonnin). She shows antagonistic intersubjectivity when she blames the neglect and lack of education of the staff of the school after her schoolmate dies due to sickness: "I grew bitter, and censured the woman for cruel neglect of our physical ills" (Bonnin). Her fear of the white man's devil leads to the destruction of its image in a book containing stories about religion, thus offering another example of antagonistic intersubjectivity.

Just like in the case of Jacobs and the protagonist of Gilman, the objectified victim at first appears to act according to socially accepted scripts, which later gives way to behavioral patterns resembling the radical performative. What is unique, however, in the present case is that there are no scripts applying to Native Americans as they were seen mostly as the reification of the Noble Savage stereotype at best, or were not even considered part of Anglo society. Nevertheless, Bonnin and her fellow captives are forced to accept the school rules and act accordingly.

The beginning of her subjectivation process is marked by the episode during which she is sent to kitchen duty for the violation of school rules. She is selected to mash turnips for dinner and in a form of the theatrical performative she does what she is told. But she hits the turnips with such force that eventually breaks the jar and the hated vegetable mass falls on the floor. This way a theatrical performative 
act turns eventually into the radical performative, a subversive deed, and offers an example of subjectivation.

It must be reiterated that her ordeal is mostly psychological as she is rarely abused physically. The cutting off her hair is motivated mostly by hygienic reasons, with a hidden agenda of breaking her will and robbing her individuality. The power she faces is of course the WASP society, the palefaces, and the boarding school itself. It is noteworthy that she refers to white people as palefaces, offering another example of antagonistic intersubjectivity. The end result of her experience is being suspended between two cultures as she cannot fully reintegrate to Indian society and she is not accepted by the mainstream either.

There are several differences between her confinement and those of Jacobs and Gilman's protagonists. Each heroine is exposed to psychological abuse, but mainly Jacobs suffers actual physical mistreatment. Both Jacobs and the anonymous main character of Gilman are subject to victimization by men, while Bonnin is abused by women. In all three cases a seemingly total control or subjection can be discerned. Spatial and temporal control is present in the case of Bonnin as her time is dominated by the bell in the school along with being forced to line up. The Indian children are deprived of the means of expression as the punishment received after falling into the snow indicates. Gothic elements also dominate the given descriptions as all three protagonists suffer ordeals in physically enclosed spaces. Enclosure, or captivity, however has different outcomes. Hiding in her grandmother's attic can be considered a jumping board to freedom for Jacobs, and enclosure in the boarding schools will present an educational opportunity that will help Bonnin to become an accomplished writer and social activist.

\section{III}

Finally, I would like to explore the limits on the contemporary regime of power, that is, the viability of absolute control over the captive. In all three cases the captors had to acknowledge the limits of confinement. Jacobs was able to fight back against the unwelcome sexual advances of her master by threatening to scream and wake up the household, and especially the wife of Dr. Flint. The husband in Gilman's story is limited in his efforts by the fact that he is the spouse of the patient, and can only threaten his wife with turning her case over to other doctors. Although both Jacobs and, to a certain extent, Bonnin were exposed to physical abuse, the effort to declare full control over the female slave and the attempt to eliminate the culture of the Native American girl eventually backfired and steeled the will of these heroines to take control of their lives. 


\section{WORKS CITED}

Bollobás, Enikő. They Aren't, Until I Call Them: Performing the Subject in American Literature. Frankfurt am Main: Peter Lang, 2010. https://doi.org/10.3726/978-3-653-00209-6

Bonnin, Gertrude S. Schooldays of an Indian Girl. 1900, www.digital.library.upenn. edu/women/zitkala-sa/stories/school.html. Accessed 23 Feb. 2020.

de Lauretis, Teresa. Technologies of Gender: Essays on Theory, Film and Fiction. Indiana UP, 1987.

https://doi.org/10.1007/978-1-349-19737-8

Gilman, Charlotte Perkins. “The Yellow Wallpaper.” 1891, www.gutenberg.org/ files/1952/1952-h/1952-h.htm. Accessed 01 Feb. 2020.

Jacobs, Harriet Ann. Incidents in the Life of a Slave Girl. 1861, www.docsouth.unc. edu/fpn/jacobs/jacobs.html. Accessed 01 Feb. 2020.

Levinas, Emmanuel. Totality and Infinity. Springer, 1980.

https://doi.org/10.1007/978-94-009-9342-6

Merleau-Ponty, Maurice. Phenomenology of Perception. Routledge, 1962.

Soja, Edward W. Thirdspace: Journeys to Los Angeles and other Real-and-Imagined Places. Malden: Blackwell, 1996. 